\title{
Delusional Disorder of Jealousy versus Bipolar Affective Disorder, Severe Manic Episode
}

\author{
Simona Trifu, Ioana Eliza Gaianu, Diab Hasan \\ University of Medicine and Pharmacy "Carol Davila”, Bucharest, Romania \\ Email: simonatrifu@yahoo.com
}

How to cite this paper: Trifu, S., Gaianu, I.E. and Hasan, D. (2019) University of Medicine and Pharmacy "Carol Davila", Bucharest, Romania. Open Journal of Social Sciences, 7, 352-361.

https://doi.org/10.4236/jss.2019.712027

Received: November 21, 2019

Accepted: December 23, 2019

Published: December 26, 2019

Copyright $\odot 2019$ by author(s) and Scientific Research Publishing Inc. This work is licensed under the Creative Commons Attribution International License (CC BY 4.0).

http://creativecommons.org/licenses/by/4.0/

\begin{abstract}
Motivation: Bipolar affective disorder superimposed on a paranoid personality structure can at various times vary various psychopathological aspects, so that at the onset of a new manic episode, until confusion or rage is evident, the one in question suggests the profile of a true delusional disorder. Objective: Presentation of a patient with a military career, his Super-Ego severely stressed by justice, fairness and limits, which overlaps a bipolar affective disorder over an event unhappy with life (the adultery of the wife), which is dressed by it, as well as by relatives and friends approach, in a symptom of the patient's disease. Hypothesis: The paranoiac's struggle with proving the truth and imposing the proof of reality breaks the fragile border of remission, causing the person concerned to make a manic episode, as the handiest way to deal with adultery. Methods: prolonged hospitalization in psychiatry, investigation of personal life history, attention to the evidence brought by the patient and understanding of the interpretive mechanism, administration of antipsychotic and mood-stabilizing treatment, individual and marital psychological counseling, psychoeducation related to the diminution of the investigative behaviors related to "ritual". Results: The patient suggests a severe manic episode with psychotic phenomena, which overlaid a confused craze after the first days of hospitalization the diagnosis suggested a delirious jealous disorder. The slip to the affective pole occurred when the reality tests supported the truthfulness of the patient's statements, the latter not intolerant of the reality and slipping into a more destructive psychosis than that of a delusional disorder. Conclusion: Involvement of the wife in the psychological management of the episode, with the restoration of the milestones of reality and the reconsideration of the participation coefficient in the family crisis of each of the partners diminished the demanding behaviors of the type: involvement of the Police, complaints, the "Othello" syndrome, with the return to the personal life.
\end{abstract}




\section{Keywords}

Bipolar Affective Disorder, Delirious Jealousy Disorder, Reality Test, "Detectives", Othello Syndrome

\section{Introduction}

The theoretical aspects of delusional disorder bring together the following aspects:

1) Non-obvious delirium (involves real-life situations: follow-up, poisoning, infection, remote love, jealousy, hypochondria) with a duration of at least 1 month - fixed delirium, unremarkable;

2) The criterion for schizophrenia has never been fulfilled (tactile and olfactory hallucinations may be present, but they are related to the delusional theme);

3) The patient normal functioning is not markedly damaged; the behavior is not obviously bizarre or strange, except for the delirium;

4) If there were dispositional episodes in parallel with the delirium, their duration was shorter than the duration of the delirium;

5) The symptoms are not due to a general medical condition or the consumption of substances.

We can find the following types of delusional disorder: erotomaniac; of grandeur, jealousy, of persecutor type, somatic type, of mixed type.

In what regards the post-psychotic depression:

1) The criteria for major depressive episode are met-it must include: depressive mood, which is not due to the adverse effects of the drugs, nor to the negative symptoms of schizophrenia;

2) Major depressive episode only in the residual (or even remote) phase;

3) Major depressive episode is not due to a general medical condition or substance abuse.

Its characteristics are: appears immediately after remission of active phase symptoms; it occurs in 25\% of patients; antidepressants should be added; the prognosis is worse, with frequent relapses and increased suicide risk.

Predisposing factors: poor premorbid functioning; schizoid personality; insidious debut; AHC of mood disorders.

The patient (let's call him B) at the age of 39 is admitted non-voluntarily to psychiatry in 2019. Among the reasons for the hospitalization we note aggression, logorrhea, hetero-aggressiveness, flight of ideas, incoherence between ideas and words.

Anamnesis: His wife comes to the police station, reporting that her husband has become aggressive and does not want to go to the hospital voluntarily, threatening her, being afraid to live with him. The wife also requests an ambulance crew.

The police claim that Mr. B. was not aggressive, but only spoke incoherently.

Thus, Mr. B. is admitted for the following reasons, according to the declara- 
tion of his wife, who requested the admission:

- Aggressivity

- Logorrhea

- Psychological pressure on the wife and the child

- Accusations against the wife that she would like to poison him

- Inconsistency in thinking

- Unjustified expenses

- Desire to control

- Conflicts with the wife and the child

Also, the woman mentions that for about ten months, the husband's behavior has changed. He:

- sleeps very little;

- consumes in excess coffee and energizers;

- is irascible;

- permanently controls her calls on the phone.

His wife also states that he controls it from a financial point of view: "He takes all my money; he pays the installments at home." Mister B. is in conflict with the wife's family and sometimes forbids her to go to service. The patient also accuses her of having an extra-marital relationship, stating that she has evidence in this regard (recordings made using a smartphone application). The wife is also accused of lying to him, despite the fact that the husband still has "all the arguments that things are not so".

\section{Description of the Patient Status}

From the observation sheet we note that the patient is brought by ambulance to the guard room, with his wife, being dysphoric and having ideas, verbal hetero aggressiveness and potentially aggressive towards his wife. The patient declares that he wants to interrupt the conjugal relationship: "I want to break away from my wife because it only hurts me."

Mister B seems uninhibited, his need for sleep being lowered according to his wife's statements (he had not slept for about 27 hours), with symptoms that gradually increased, in the context of partial compliance with the underlying treatment for the bipolar affective disorder he suffers (Depakine $300 \mathrm{mg} /$ day). The patient refuses to take his treatment and is thus admitted in a non-voluntary regime according to the Mental Health Law.

Workplace: The patient has a workplace within the Army (Communications). He changed the job three times, to three different units, the first being the one that he had adapted best. He states that he had some conflicts with his new boss at the current unit, a boss he dislikes, as opposed to his former boss, whom he seems to bear the esteem of and who he has attached to.

At the same time, there was also an exchange of replies between the two, the patient feeling offended and stigmatized in front of colleagues: "nine years offended me", "how to live nine years with the boss and make you stupid", "in- 
competent and to tell you that nothing you do is wrong?", "resign, you have limited abilities!" It is also emotionally affected by the measures taken by the medical decision, namely, the fact that it cannot participate in the training camps and cannot do his job in the unit (among other limitations). He claims that he has never had penalties for disciplinary violations. It continues to work and at present, its functioning on a professional level is not significantly damaged.

Family: The man has a child of 11 years with his current wife, with whom he has been married since 2002. The patient adds regarding the child: "I am sure that is mine; I have put my problem in the past, but it is mine".

Also, the person in question seems to be uncompromising regarding his marriage. He has a set of principles of the "all or nothing" type, which he wishes to respect precisely: "Three things I hate and keep in mind all her life ... if she violated them all is over ..."

Currently, the patient seems to want to divorce his wife, declaring that he has already prepared the necessary documents. "The wife does not want to divorce; I want to try to stop me." Later, he argues that his wife "is not decided", "her third time, every time I wanted to divorce, I came to psychiatry" and is aware of the impact about this possible divorce on the child: "I think of the child, that he is 11 years old and I will split him in two if I divorce ..."

We noticed that patient has no psychiatric hereditary-collateral history and he is a high school graduate and, then, a Military School graduate.

The relationship with his parents was harmonious: "I kept calling moms and dads". His mother is a technical engineer, and his father worked in the Police, until the patient was 35 years old. The patient also has a brother in military service and a sister working in a bank.

Pathological personal history: The patient is known with bipolar affective disorder, for which he was admitted twice in the history, in 2010 and 2012, being treated with Depakine $300 \mathrm{mg}$ once daily, at lunch, affirmatively compliant at treatment.

At the general clinical examination nothing pathological from the somatic point of view is noticed.

At the psychic examination, the patient is aware, but weakly cooperative, restless psycho-motor, properly dressed and with the maintained hygiene.

The psychological factors revealed:

- Mimics, gesture: hypermobile, expansive, with a high pitch voice;

- Attention: voluntary hypo-procession and spontaneous hyperproxia;

- Memory: hypomnesia of fixation;

- Perception: lower the perceptual threshold but deny hallucinations at the time of examination;

- Thinking: accelerated rhythm of verbal ideas, flight of delights, delusional idea of grandeur, marked suspicion, discourse centered on family conflict with himself, which he thinks has an extra-marital relationship; 
- Affect: it is altered, with expansiveness, elevated disposition with dysphoric potential and impulsivity, emotional lability. It presents physical-verbal heterosexual aggression towards his wife;

- The day/night rhythm is altered, with mixed insomnia, but which the patient denies: "I cannot sleep continuously, I think no one can", "how many times do you wake up at night?", "Is there a man who will sleep uninterrupted from when to bed and until morning?"

\section{The Medical Interview}

During the medical interview, the patient wants his words to be recorded precisely "noted there"-with an exaggerated tendency to be "right to the end" ("you can also check"). The fact is supported by the request for a more correct diagnosis of his condition, in order to communicate it to the superiors of the workplace, in order to take the necessary measures. The patient claims that he wants to divorce and states that he was physically aggressive to some extent towards his wife, when she denied the veracity of the phone recordings: "part, seven on the other, when he denied my evidence and made me crazy, paranoid", "My intention was not to beat her, but to divorce", "I am very calm, another was walking and stepped on my feet", "If I recognized, I did not even touch it with a palm, we divorce directly".

The patient feels underestimated, denying jealousy: "Jealousy is one, I am not jealous, but I am not stupid ... the moment you deceive me ..." His main goal is for the wife to acknowledge, to confess what he is already saying: that he salads. He suspects that it poisoned him (poisoning delirium) by slipping a substance into the morning coffee. He argues at one point that "poison" is actually a compound based on anabolic steroids, because since drinking, it has erectile dysfunction, until then, having no problem in this regard. He maintains that the couple's sexual life did not present difficulties, from his point of view. He goes on to conduct laboratory investigations to detect the so-called substance. Later he gave up this delirium of poisoning, claiming that "I am that stupid, if he wanted to kill me, he would do it for a long time" [1].

During the current hospitalization he had a moment when he called the Police in the middle of the night, because his wife did not answer his phone. Because he is "worried", he calls for a police crew to move to the address where he lives, to check the safety of his wife and child. In fact, under the impetus of delusional ideas of jealousy, such as his wife cheating on her boss at work, not being able to verify the truth himself, he asked the Police to go to his home, the crew finding nothing but his wife and child sleeping.

The patient seems to have bipolar affective disorder developed on a paranoid type personality, focused on a single theme, suspected that his wife is unfaithful, which dominates his mental life. He constantly seeks to prove his wife's guilt, the reality of which is not aligned with his wife's denial. However, the trigger for his paranoid idea seems to be unrealistic [2]. The patient holds on the phone or a 
series of records made with an application for supervised children, the records appearing to demonstrate what the patient supports, to the surprise of the doctors. There is also an episode in which the patient, finding some new clothes among his wife's things, interprets them as being acquired by the lover.

The patient collects these clothes and brings them to the hospital, considering them as additional evidence for his wife's guilt.

Thus, against the background of his manic episode and paranoid tendencies, there is an intensification and perpetuation of the ideas of jealousy, which seem, after all, to have a real motivation. This core of truth, superimposed on its psychiatric pathology, results in a heterogeneous behavior, obsessed with the central idea of being deceived, the patient stubbornly proving the truth of the situation. The occupation for fairness and truth is illustrated: "note there", "I am a correct man", "I show you", "you can verify", trying at any price to show that what he lives is real.

In the absence of his wife, he does not appear to be violent/aggressive, but only dominated by the idea of demonstrating his guilt and of demonstrating that what he has heard and seen is real. The negative interpretation of the events, the marked suspicion (the fact that the wife does not answer the phone) is again a feature of the paranoid personality disorder.

The patient looks for evidence that he is deceived in everything his wife has said or done, constantly follows her, invades her personally and tries to control her, to limit her autonomy (asks her to give up the work place, where she is supposed to have intimate dating with lover).

His efforts to prove that his wife cheats him go so far as to communicate with the wife of the suspicious lover. The patient writes messages (but in a respectful, friendly tone), trying to clarify the situation, to understand what is happening. However, he is struck by an atypical attitude of the lover's wife. She denies any connection between her husband and the patient's wife, making such a story impossible. Obviously, it is a defense mechanism (i.e., denial), the woman not wishing to know that she was cheating, in order to keep her marriage quiet and avoid anxiety [3].

In the face of this response, Mr. B. becomes increasingly confused and frustrated in his attempt to prove his wife's guilt. Animated by the energy of the manic episode, all his attention is directed to a single subject, all his efforts go in one direction: the investigation and the demonstration of being deceived. Also, his suspicion and investigations seem to extend in retrospect to the child as well, the patient stating that in the past he has raised the issue of paternity: "I have had problems in the past, but now I know that this child is mine". This demonstrates the tendencies towards paranoid thinking since early in the relationship [4].

The delusion of jealousy does not seem to be accompanied by the alteration of perception (hallucinations or commentary voices), yet the patient maintains a firm contact with reality. 
The belief that his wife not only cheats him, but also wants to "hurt her" is supported by a recording in which she communicates to her lover that he has put something in her husband's coffee to calm him down. The patient deliriously interprets this information and claims that from the day he drank that coffee, he started to have erectile dysfunction. His interpretation seems strange compared to the term "poisoning", but he has a possible explanation in one of the conversations between wife and lover, regarding the sexual life between the patient and his wife [5]. Apparently, the recorded discussion addresses the subject of the patient's inability to sexually satisfy his life partner. This may be the starting point of the cause of the inhibition of sexual reflexes, a potentiated situation and of the tense relationship that exists at the moment between the spouses, Mr. B. claiming that he wishes to divorce his current wife, as well as the possible adverse effects of the medication.

The development of jealousy is often associated with impotence in men and sexual dysfunction in women. This psycho-sexual dysfunction is rather a consequence, than the cause behind jealousy, while amplifying the delusional idea of jealousy (Seminars in General Adult Psychiatry).

Despite the diagnosis of bipolar affective disorder and delirium or jealousy structured against the background of paranoid personality, however, the patient does not seem to abuse substances (other than coffee, energy and tobacco) [6]. Regarding tobacco, he states that he currently smokes three packs of cigarettes a day, due to the fact that he is admitted (possibly due to the manic episode). Neglect thoughts of self-aggression [7].

Also, although it has impulsivity (give the Police a phone to go to his home and check his wife) and hetero-aggression (predominantly verbal), the person in question does not resort to acts of violence against the so-called lover, focusing more on confirming the facts, by demonstrating his perspective before the arguments against what is brought to him. Frustration in the face of discordant data is tolerated with difficulty [8].

Summarizing, the patient suspects his wife of infidelity, follows her through the phone, even resort to extreme measures, such as calling the law enforcement agencies to verify the suspicion of infidelity, collecting "evidence" to support his point of view: audio recordings, clothes. He also tries to limit his wife's autonomy by forbidding him to go to work. Ideas with paranoid content seem to have their roots in the past, the patient stating at one point that he had no suspicion that he is not the father of the child, who is now 11 years old: past, but now I know it's mine".

\section{Diagnosis and Discussions}

\subsection{Main Diagnosis}

In the Axis I: Manic episode with psychotic phenomena within the bipolar affective disorder-manic confusion-accompanied by the decrease of the need for sleep, irritability, wear and tear, ideas flight, distractibility, circumstantiality, res- 
tlessness and psycho-motor agitation.

In the Axis II: The patient also has a paranoid personality disorder, circumscribed by the idea of infidelity and, to a lesser extent, the idea of persecution regarding the workplace.

First differential diagnosis: Delirious disorder, characterized by:

- Non-bizarre delirium (possible: tracking, poisoning, infecting, being loved, cheating, hypochondriac ideas) - at least one idea/month.

- Criteria for schizophrenia (hallucinations, delirium, disorganization of thinking and activity, negative symptoms) have never been met; delirious tactile, olfactory hallucinations may occur. No other hallucinations appear, as in schizophrenia.

- Apart from the impact of delirium, the functioning of the person concerned is not affected.

- In this case, the subtype is the delirium of jealousy, persecution and poisoning.

\subsection{Other Possible Differential Diagnosis}

1) Othello syndrome-also called soft jealousy or conjugal paranoia-is the origin of the name in the play of William Shakespeare, in which the protagonist finally kills his wife, named Desdemona. It mainly affects men without a history of mental illness. The syndrome involves delusional ideas of jealousy, which extremely deviate the behavior: pursuit, violence, marked suspicion, distrust, limiting the autonomy of the other. This set of behaviors is not evidence-based and feeds on the small things that the partner does, but which are interpreted deliriously. It is associated with alcohol abuse, has potential marked by hetero aggression, even with homicide, the only solution being separation, divorce or even death of the partner [9].

In this case, delusional ideas of jealousy are between truth and falsehood, between reality and the imaginary. At first glance, the patient's suspicion seems unjustified, with the history of bipolar affective disorder making it more likely the first differential diagnosis of delirious disorder with the theme of jealousy (the psychotic elements are, in fact, in the manic episode). However, the "evidence" presented is plausible and shows that the patient's suspicion is indeed justified. Non-bizarre delirium is defined as delirium with themes that can represent real life situations. This case shows that sometimes, under seemingly delusional behavior, fragments of truth can be hidden, which feeds, creates a matrix on which the patient weaves his delirium in a systematic, organized, plausible way [10].

Affective participation can be extremely intense, jealousy is a strong, explosive feeling, which may in some cases be the source of particularly violent behaviors.

The components of physical aggression or substance abuse are absent in this case, the purpose of the patient being rather the demonstration of the truth, the guilt of the wife, compared with the punishment of her or the lover. 
In his "Did Othello Have the Othello syndrome" article in The Journal of Forensic Psychiatry, Paul Chrichton addresses a similar issue: Was Othello really driven by delusional ideas of jealousy when he killed Desdemona? How much of the story is true betrayal and how much is a delirium? (how much was he deceived rather than deluded?) [11].

2) Organic injury with psychiatric manifestations-there is no paraclinical evidence in this regard.

3) Dementia-age is not characteristic, but the onset of dementia can be a delusional disorder.

4) Parkinson's disease-no motor symptoms. It can be associated with Othello syndrome!!!!

5) Paranoid schizophrenia - the criteria for schizophrenia are missing, delirium is non-bizarre, the patient has no hallucinations, commentary voices, etc. Delusional disorder may be a byproduct of future schizophrenia.

6) Substance abuse: alcohol, amphetamine, cocaine, methylphenidate, steroid hormones, dopaminergic agonists, disulfiram.

7) Obsessive ideas-they are foreign and contradictory to the personality, they besiege the thought, they are imposed on the conscience, the patient struggles to remove them.

8) Cyclothymia (successive episodes of hypomania alternating with mild depression-minimum 2 years.

When delirium is fueled by fragments of reality, diagnosis becomes a challenge for both the clinician, and especially the patient, who lives confused in a world with conflicting messages, in search of the truth. It seems that in this case, the truth was somewhere in the middle! [12].

\section{Conclusions}

Psycho-social theories support the existence in the personal life history of factors such as:

- Physical and mental abuse

- Cruel, disordered parents, which cannot be counted

- Demanding, perfectionist climate

- Hostile, dangerous environment [13], which leads to lack of basal confidence

- Hearing loss

- Social isolation, loneliness

- Immigration

Projective psychological tests highlight:

- Concerns with paranoid, grandiose themes

- Inferiority

- Inadequacy

- Anxiety

The psychodynamic factors explain the defenses used:

1) Denial = shame, humility, inferiority is denied; 
2) Reaction formation = the transformation of unacceptable feelings into their opposite (for example: inferiority to grandeur);

3) Projection $=$ major defense $=$ unacceptable feelings are projected onto others.

As a therapist, you listen to the patient when they express their concern and respond with understanding that his delirium is disruptive and intrusive. Help the patient find a way to live more comfortable with his delirium.

You understand that this is a means of dealing with shame and inadequacy; you understand her sensitivity to any offense. Psychosis is a defensive response for someone with inadequate coping mechanisms, and psychotherapy should focus on the significance of life events and the formation of more adaptive, less devastating coping mechanisms.

Discretion and honesty are important because these patients are hypervigilant about deception and dishonesty.

The stresses that triggered the first delirium count and the case should always be considered from the perspective that other stresses can exacerbate the delirious symptoms. The patient should be helped to develop the means of coping with stress, while the therapist must find out where shame and inadequacy come from.

\section{Conflicts of Interest}

The authors declare no conflicts of interest regarding the publication of this paper.

\section{References}

[1] Gabbard, G. (2014) Tratat de psihiatrie psicodinamica. Editura Trei, Bucharest.

[2] Klein, M. (2011) Love, Guilt and Reparation Kindle Edition. Vintage, New York.

[3] Hicks, E. and Hicks, J. (2006) The Law of Attraction: The Basics of the Teachings of Abraham. Hay House, London.

[4] Krumwiede, A. (2014) Attachment Theory According to John Bowlby and Mary Ainsworth. GRIN Publishing, Munchen.

[5] Bleger, J. (1997) Psicohigiene y Psicologia Institucional/The Better to Write You (Spanish Edition). Ediciones Paidos Iberica, Barcelona.

[6] Freud, S. (2012) Beyond the Pleasure Principle Kindle Edition. Acheron Press, Oxford.

[7] Adler, A. (2010) Understanding Human Nature. Tra Edition, Martino Fine Books, Eastford.

[8] Cassidy, J. and Shaver, P. (2016) Handbook of Attachment, Third Edition: Theory, Research, and Clinical Applications. The Guilford Press, New York.

[9] Winnicott, D.W. (2005) Spaima de prabusire-Explorari psihanalitice. Editura Fundatiei Generatia, Bucharest.

[10] Sklar, J. (2017) Balint Matters: Psychosomatics and the Art of Assessment. Karnac Books, London. https://doi.org/10.4324/9780429472190

[11] Brazelton, B. and Sparrow, J. (2015) Discipline: The Brazelton Way (A Merloyd Lawrence Book). 2nd Edition, Da Capo Lifelong Books, Lebanon.

[12] Einstein, A. (2014) The World as I See It. Snowball Publishing, New York.

[13] Erikson, E.H. (1993) Childhood and Society. W. W. Norton \& Company, New York. 